\title{
Thermoelectric Properties of Carbon Nanotube and Nanofiber Based Ethylene-Octene Copolymer Composites for Thermoelectric Devices
}

\author{
P. Slobodian, ${ }^{1,2}$ P. Riha, ${ }^{3}$ R. Olejnik, ${ }^{1,2}$ M. Kovar, ${ }^{1,4}$ and P. Svoboda ${ }^{2,4}$ \\ ${ }^{1}$ Polymer Centre, Faculty of Technology, T. Bata University, T.G.M. 275, 76272 Zlin, Czech Republic \\ ${ }^{2}$ Centre of Polymer Systems, University Institute, T. Bata University, Nad Ovcirnou 3685, 76001 Zlin, Czech Republic \\ ${ }^{3}$ Institute of Hydrodynamics, Academy of Sciences, Pod Patankou 5, 16612 Prague 6, Czech Republic \\ ${ }^{4}$ Deptartment of Polymer Engineering, Faculty of Technology, T. Bata University in Zlin, T.G.M. 275, 762 72 Zlin, Czech Republic
}

Correspondence should be addressed to P. Slobodian; slobodian@ft.utb.cz

Received 12 June 2013; Revised 30 August 2013; Accepted 31 August 2013

Academic Editor: Jung-Kun Lee

Copyright (C) 2013 P. Slobodian et al. This is an open access article distributed under the Creative Commons Attribution License, which permits unrestricted use, distribution, and reproduction in any medium, provided the original work is properly cited.

\begin{abstract}
Polymer composites have been created from multiwalled carbon nanotubes or carbon nanofibers and ethylene-octene copolymer. The composites have thermoelectric properties and exhibit thermoelectric effect, that is, the conversion of temperature differences into electricity. The thermoelectric efficiency of created composites with nanotube or nanofiber concentration of $30 \mathrm{wt} \%$ evaluated by a thermoelectric power at room temperature is $13.3 \mu \mathrm{V} / \mathrm{K}$ and $14.2 \mu \mathrm{V} / \mathrm{K}$, respectively. The flexible thermoelectric device (thermopile) was constructed with three different composite legs to produce electric current and the output voltage was measured in the range of temperature difference from -15 to $25^{\circ} \mathrm{C}$.
\end{abstract}

\section{Introduction}

Thermoelectric devices are capable to convert thermal energy into electricity when there is a different temperature between the hot and cold junctions of two dissimilar conductive or semiconductive materials. Thermoelectric electricity generation is based on a phenomenon called Seebeck effect. The heat supplied at the hot junction causes an electric current to flow that can be harnessed as useful voltage [1]. At the atomic scale, the temperature difference causes charge carriers in the material to diffuse from the hot side to the cold side.

The classical thermoelectric materials used in devices are metals and metallic alloys, for example, $\mathrm{Al}, \mathrm{Cu}, \mathrm{Ni}, \mathrm{Bi}, \mathrm{Sb}$, chromel, and alumel as well as semiconductors $\mathrm{PbTe}$ and $\mathrm{Bi}_{2} \mathrm{Te}_{3}$. The common feature of these materials is not only high thermoelectric efficiency but also high cost of production, weight, and scarcity. Consequently, the alternative thermoelectric materials are investigated including organic polymers with carbon nanotube fillers [2-8]. Though the thermoelectric efficiency of organic thermoelectrics is currently lower than that of the inorganic ones, their mechanical flexibility, processibality, light weight, and low manufacturing costs may be desirable in applications.

The composites containing pristine or doped carbon nanotubes and polymers like polyvinylidene fluoride $[2,3]$, polyester [4], polyaniline [5], polyvinyl acetate $[6,7]$, and poly(3-hexylthiophene) [8] have shown great promise as ntype or p-type thermoelectrics. The thermoelectric figure of merit of the polymer composites is typically in the range $0.001-0.01$ at room temperature. Though the thermoelectric efficiency is considerably lower than that of classical thermoelectric materials, the polymer thermoelectrics may be, in view of other properties, a desirable technological and environment-friendly alternative.

Traditional inorganic thermoelectric semiconductors have some limitations in their applications like low efficiency and high material cost of low-abundance materials [9] in addition to brittleness and difficulty in large-area deposition 


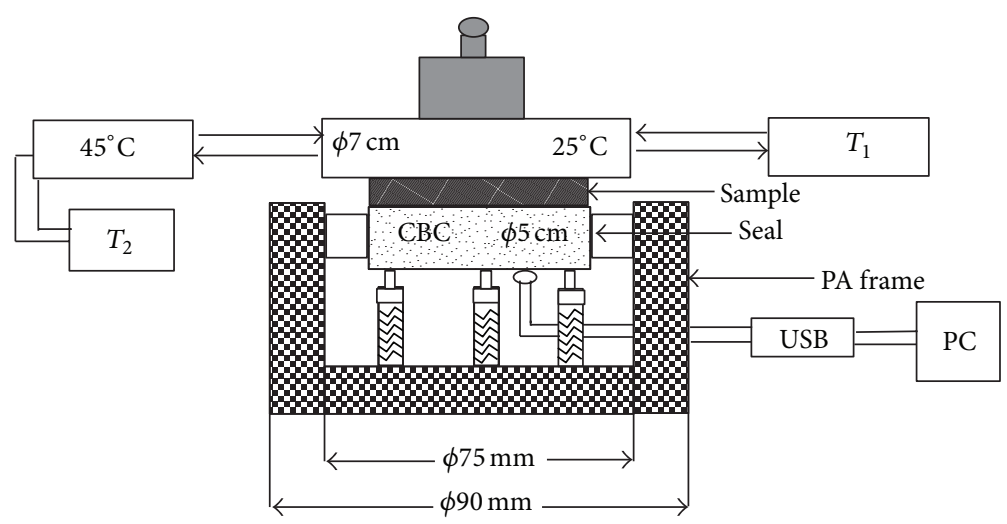

FIGURE 1: Experimental setup for the measurement of thermal conductivity of composites.

[10]. On the other hand novel organic semiconductors (molecules, oligomers, and polymers) possess some unique features. There can be mentioned their low density, low manufacturing cost, easy synthesis, and processing and versatile processability; they have low thermal conductivity, and they are flexible finally with natural abundance of environmently friend-materials [11, 12]. They can be composed of net organic conducting polymers [11] or copolymers [13] even as a combination of polymer-inorganic materials [14] or as a polymeric nanocomposite mainly in course to further improve its thermoelectric efficiency. Metal nanoparticles [12] or different kinds of carbon nanotubes, CNT, as usualy used as as an electrically conductive filer used in either non-conducting polymeric matrix (PVAC) [7] or conductive polymer matrix $[8,15-17]$.

In the present paper, the effect of different carbon-base fillers in ethylene-octene copolymer composites on their thermoelectric power at room temperature $22^{\circ} \mathrm{C}$ was studied. The composites were prepared with pristine multiwalled carbon nanotubes (MWCNT) and carbon nanofibers (CNF). The thermoelectric efficiency of the composites was calculated on basis of the measured electrical and thermal conductivities and the induced electric voltage.

\section{Experimental}

The ethylene-octene copolymer (EOC) with $45 \mathrm{wt} \%$ of octene content (ENGAGE 8842) was purchased from Dow Chemicals. The density of EOC was $0.8595 \mathrm{gcm}^{-3}$.

The purified multiwalled carbon nanotubes (MWCNT) produced by acetylene chemical vapor deposition method were purchased from Sun Nanotech Co., Ltd., China with purity $>90 \%$ and electrical resistivity $0.12 \Omega \mathrm{cm}$. Further details on the nanotubes denoted further on MWCNT(Sun) were obtained by means of the transmission electron microscopy analysis presented in our previous papers [18, 19]. From the corresponding micrographs the diameter of individual nanotubes was determined to be between 10 and $60 \mathrm{~nm}$, their length from tens of micrometers up to $3 \mu \mathrm{m}$. The maximum aspect ratio of the nanotubes is about 300 .

The other kind of MWCNTs produced by chemical vapor deposition and marked Baytubes C70 P was provided by the Bayer MaterialScience AG, Germany (C-purity > $95 \mathrm{wt} \%$, outer mean diameter $\sim 13 \mathrm{~nm}$, inner mean diameter $\sim 4 \mathrm{~nm}$, length $>1 \mu \mathrm{m}$, and declared bulk density of MWCNT of agglomerates of micrometric size $45-95 \mathrm{~kg} / \mathrm{m}^{3}$ ). The nanotubes are denoted further on MWCNT(Bayer).

The carbon nanofibers with trade name VGCF (Vapor Grown Carbon Fibers) were supplied by Showa Denko K.K. (Japan). The fiber diameter was $150 \mathrm{~nm}$, length $10 \mu \mathrm{m}$, and electrical resistivity $0.012 \Omega \mathrm{cm}$.

The composites were prepared by ultrasonication of dispersions of MWCNT or CNF in EOC/toluene (5\% solution of EOC in toluene). The chosen filler concentration in the composites was $30 \mathrm{wt} \%$ which is well above the percolation threshold. The sonication process was carried out using thermostatic ultrasonic bath (Bandelin electronic DT 103H) for $3 \mathrm{~h}$ at $80^{\circ} \mathrm{C}$. Then the dispersion was poured into acetone which is not solvent of EOC but mixes with toluene and forms a precipitate. Finally, the composite sheets were prepared by compression molding at $100^{\circ} \mathrm{C}$.

Morphology of the prepared composites was studied using scanning electron microscope (SEM). SEM analysis was carried out using Vega II LMU (Tescan, Czech Republic) with a beam acceleration voltage set at $10 \mathrm{kV}$.

The apparent electrical conductivity of composites, hereafter called simply electrical conductivity, was measured by a two-point method using Broadband Dielectric/Impedance Spectrometer (Novocontrol Technologies) in $\mathrm{N}_{2}$ atmosphere across the composite sample thickness. Thickness of the sample was about $1.1 \mathrm{~mm}$ and the diameter $20 \mathrm{~mm}$. The values of electrical DC conductivity were determined at frequency $0.1 \mathrm{~Hz}$ when the conductivity is constant.

The apparent thermal conductivity of the composites, hereafter called simply thermal conductivity, was measured using experimental setup shown schematically in Figure 1 according to the method described in $[20,21]$. At the beginning of the measurement, the central brass cylinder (CBC) was annealed to a temperature $45^{\circ} \mathrm{C}$ using a hollow cylinder connected to a water thermostat. Then the hollow cylinder was removed and replaced by the composite sample (diameter $5 \mathrm{~cm}$, thickness $2 \mathrm{~mm}$ ) on top of which the hollow brass cylinder kept at $25^{\circ} \mathrm{C}$ is then placed and loaded to ensure good contact with the sample. The software LabVIEW 


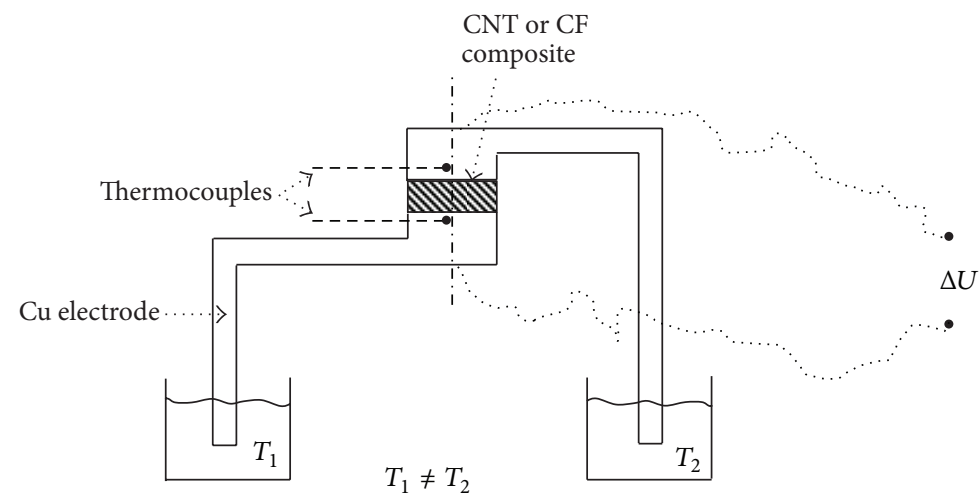

FIGURE 2: Schematics diagram of the setup for the measurement of electric voltage induced in the composite in response to a temperature difference.

SignalExpress 2.5 was used for the decreasing temperature acquisition from CBC. The mathematical analysis of the measured data and calculation of thermal conductivity is presented in detail in Section 3.

The thermoelectric power measurement was carried out for all the samples using a setup illustrated in Figure 2. The schematic diagram shows that the circular composite sample (diameter $20 \mathrm{~mm}$, thickness $2 \mathrm{~mm}$ ) is placed between two copper electrodes. The ends of each $\mathrm{Cu}$ electrode were immersed in a thermostatic silicone oil baths set to different temperatures. The temperature at the copper/composite interfaces was measured by a digital thermometer. The arising thermoelectric current is measured with a Keithley 2000 Digital Multimeter.

\section{Calculation of Thermal Conductivity}

To describe the temperature time dependence of the central brass cylinder (Figure 1), the following heat balance equation is used [21]:

$$
-C \frac{d T}{d t}=\frac{s \lambda\left(T-T_{2}\right)}{h}+\psi\left(T-T_{2}\right),
$$

where $T$ denotes the temperature of the CBS, $C$ the heat capacity of the CBC, $t$ the time, $s$ and $h$ the sample area and thickness, respectively, $\lambda$ the thermal conductivity of the sample, $T_{2}$ the temperature of hollow brass cylinder $25^{\circ} \mathrm{C}$, and $\Psi$ the coefficient accounting for a heat loss. The first term of (1) on the right side represents heat flow through the measured sample and the second one the heat loss to surroundings.

The left side of (1) represents heat output of the central brass cylinder form monitored by the temperature $T$ from the initial temperature $T_{1}=T(t=0)=45^{\circ} \mathrm{C}$ to the equilibrium temperature $T_{2}=25^{\circ} \mathrm{C}$. The solution of (1) is

$$
T=T_{1}-\left(T_{1}-T_{2}\right) \exp \left[-\left(A_{1}+A_{2}\right) t\right],
$$

where $A_{1}$ and $A_{2}$ are coefficients, $A_{1}=s \lambda / h C$, and $A_{2}=$ $\psi / C$.

The heat loss was determined by the so called "the blind experiment". The heat loss was determined by the so called "the blind experiment". In this course the specimen with very small thermal conductivity (expanded polystyrene with $\lambda=$ $0.035 \mathrm{Wm}^{-1} \mathrm{~K}^{-1}$ ) is used as calibration standard. Equation (2) can be simplified to $y=y_{0}+a \exp (-b t)$ for the nonlinear regression of the measured temperature decay of the CBS. From a nonlinear regression of "the blind experiment" the coefficient $b$ follows equal to the heat loss coefficient $A_{2}=$ $0.000368 \mathrm{~s}^{-1}$. Thermal capacity of the central brass cylinder was determined $C=94.107 \mathrm{JK}^{-1}$. The size of samples $h=$ $0.002 \mathrm{~m}$ and $s=0.001963 \mathrm{~m}^{2}$.

To determine, for example, the thermal conductivity of CNF/EOC (30 wt\%) composite, the coefficient $b$, obtained from the fitting of the time dependent temperature decrease of the central brass cylinder, is $b=0.001211 \mathrm{~s}^{-1}$. Consequently, $A_{1}=b-A_{2}=0.001211-0.000368=0.0008422 \mathrm{~s}^{-1}$, and the thermal conductivity of the composite,

$$
\begin{aligned}
\lambda & =\frac{A_{1} h C}{s} \\
& =\frac{0.0008422 * 0.002 * 94.107}{0.001963}=0.8081 \mathrm{Wm}^{-1} \mathrm{~K}^{-1} .
\end{aligned}
$$

\section{Results}

Figure 3 shows SEM analysis of the surface of multiwalled carbon nanotubes and carbon nanofibers networks, respectively. The networks were formed from the aqueous dispersion of MWCNTs or CNFs on the surface of the interdigitated electrode by a drop method. The obtained micrographs in Figure 3 show some differences, namely, the larger diameters of pores of CNF layer than the ones of the carbon nanotube layer. The cross-sections of the composites in Figure 4 show good dispersion of MWCNT(Sun) and CNF fillers.

The effect of the filler concentration on the electric $(\sigma)$ and thermal conductivity $(\lambda)$ of composites is presented in Figure 5. The figure demonstrates that both conductivities considerably increase with the filler concentration when a percolation threshold is reached. The results show that in the composite with longer CNFs (about $10 \mu \mathrm{m}$ ), the conducting paths are created at lower concentration in comparison 
TABLE 1: Thermoelectric properties of the composite samples. The electrical conductivity $\sigma$, the thermal conductivity $\lambda$, the thermoelectric power $S$, the power factor $S^{2} \sigma$, and the figure of merit $Z T$.

\begin{tabular}{lccccc}
\hline Sample & $\sigma(\mathrm{S} / \mathrm{m})$ & $\lambda(\mathrm{W} / \mathrm{mK})$ & $S(\mu \mathrm{V} / \mathrm{K})$ & $S^{2} \sigma\left(\mu \mathrm{W} / \mathrm{mK}^{2)}\right.$ & $Z T$ \\
\hline CNF/EOC & 0.21 & 0.8081 & 14.2 & $4.2 \times 10^{-5}$ & $1.5 \times 10^{-2}$ \\
MWCNT(Sun)/EOC & 0.13 & 0.4087 & 13.3 & $2.3 \times 10^{-5}$ & $1.6 \times 10^{-2}$ \\
MWCNT(Bayer)/EOC & 0.12 & 0.2859 & 6.4 & $4.9 \times 10^{-6}$ & $5.0 \times 10^{-3}$ \\
\hline
\end{tabular}

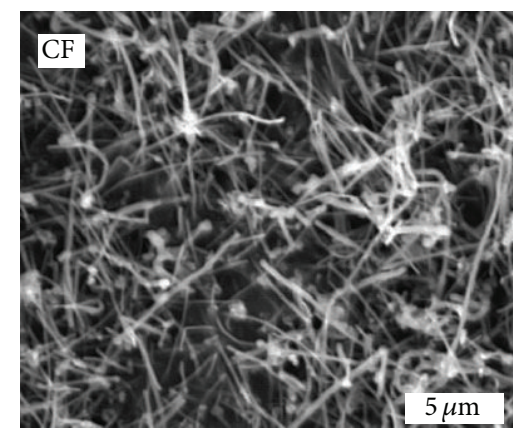

(a)

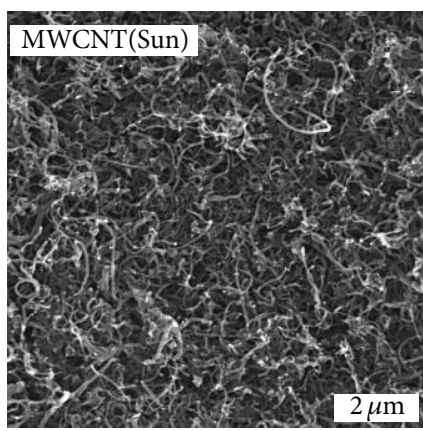

(b)

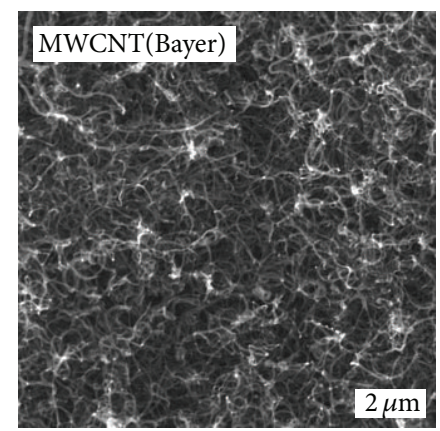

(c)

FIGURE 3: SEM micrographs of the layer surface made of three different materials: (a) carbon nanofibers, (b) MWCNT(Sun), and (c) MWCNT(Bayer).
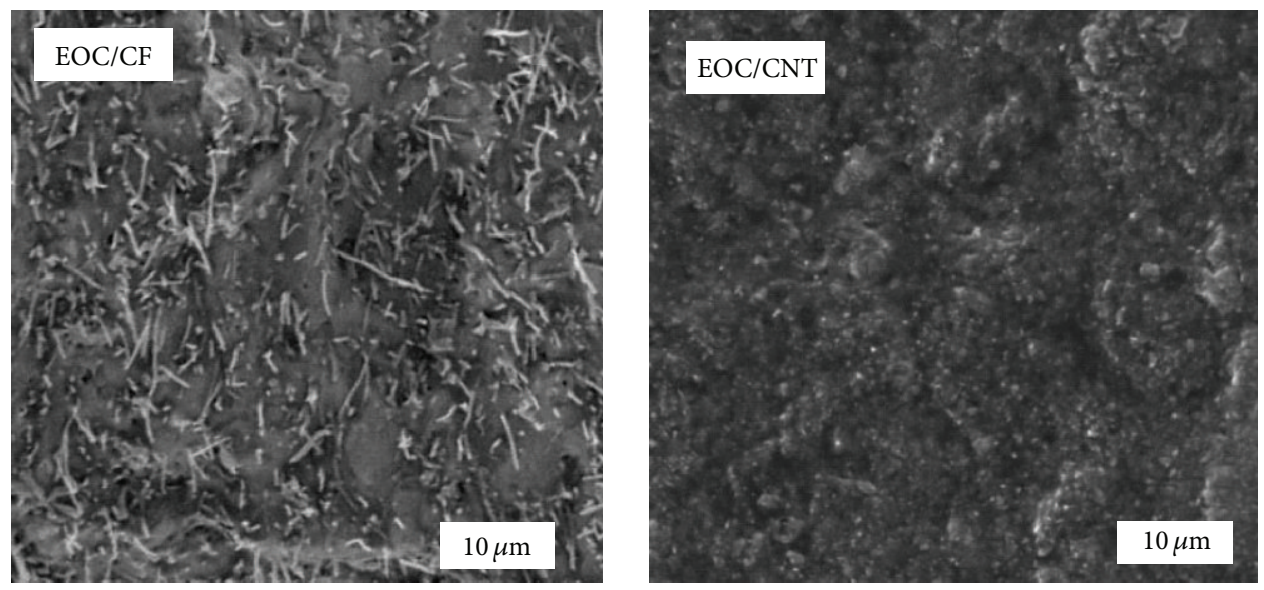

FIGURE 4: SEM micrographs of the cross-section of CNF/EOC and MWCNT(Sun)/EOC composites.

with EOC composite filled by MWCNT(Sun)s (length about $3 \mathrm{~mm})$. The lower resistivity of CNFs $(0.012 \Omega \mathrm{cm})$ with respect to MWCNT resistivity $(0.12 \Omega \mathrm{cm})$ also probably contributes to the electrical conductivity difference between both composites. For the evaluation of the composite thermoelectric properties, the composites with the filler concentration $30 \%$, what is well above the percolation threshold, were used. The values of conductivities for this filler concentration are summarized in Table 1 among other values of thermal properties.

Figure 6 shows the values of induced electric voltage in response to a temperature difference across the measured sample of all investigated composites. From the slope of the linear temperature-difference $(\Delta T)$ dependence of resulting electric voltage $V_{\mathrm{TEV}}$, the thermoelectric power $S$, which is defined $S=V_{\mathrm{TEV}} / \Delta T$, can be obtained. The thermoelectric power is comparable for CNF and MWCNT(Sun) composites (Table 1). On the other hand, the electrical conductivities differentiate the values of power factor $\left(S^{2} \sigma\right)$ of $\mathrm{CNF}$ and MWCNT(Sun) composites in the dimensionless figure of merit $Z T\left(Z T=\left(S^{2} \sigma / \lambda\right) T\right.$, where $T$ is temperature). The power factor is important value since it is directly related to the usable power attainable from the thermoelectric material [2]. The factor thus evaluates thermoelectric performance when precise data on the thermal conductivity are not available. Obviously, a high value of the figure of merit $Z T$ is achieved by creating a material with a high power factor and low thermal conductivity.

Figure 7 shows thermoelectric device (thermopile) built up of MWCNT (Bayer) and CNF/EOC flexible composite films and the schematic diagram showing the material junctions in series alternating hot/cold temperatures with each 


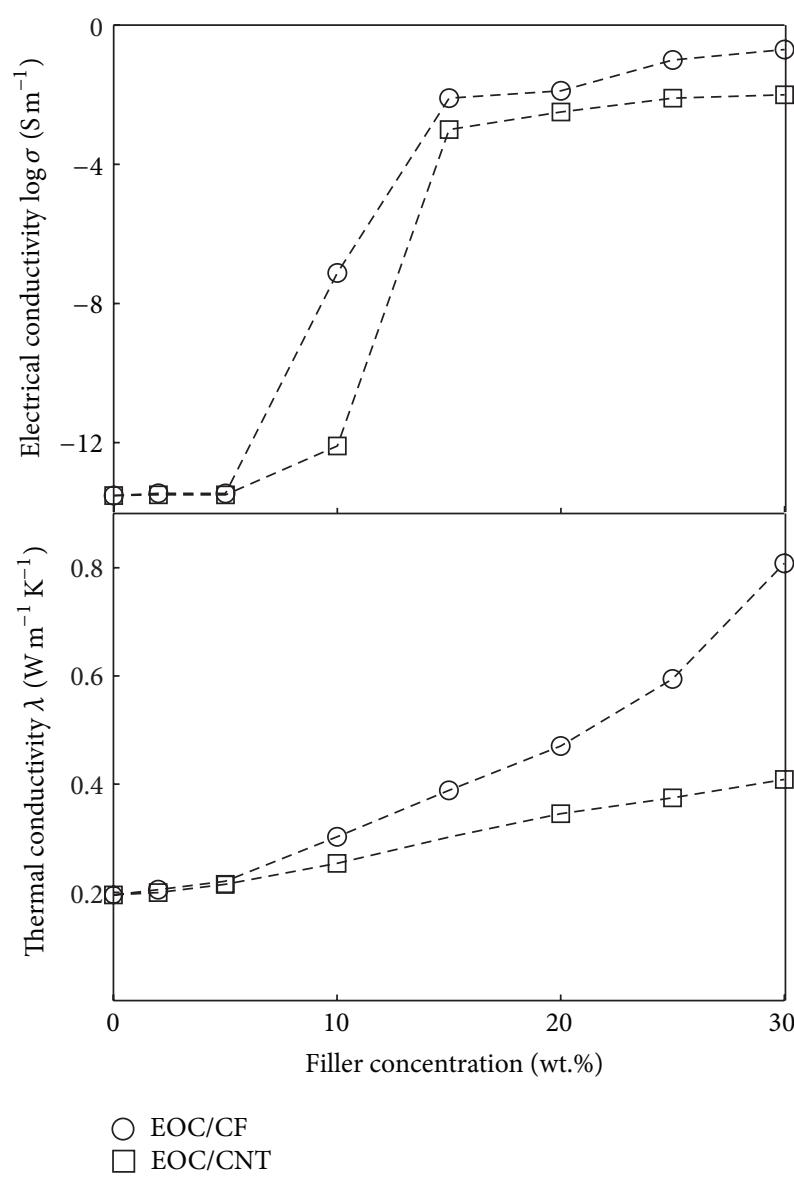

FIGURE 5: Filler concentration-dependent electrical and thermal conductivities of NCF/EOC composite and MWCNT(Sun)/EOC composite.

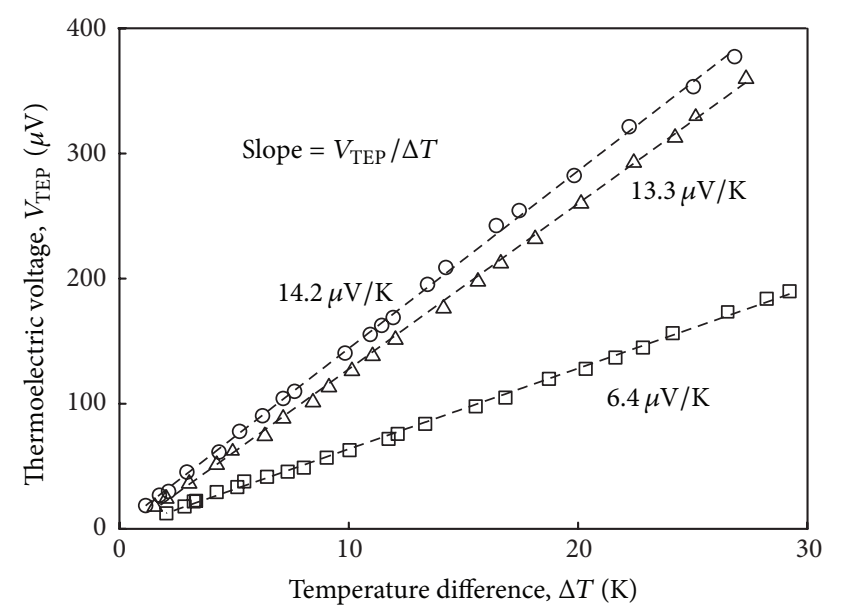

$\circ \mathrm{Cu}-\mathrm{EOC} / \mathrm{CF}$
$\triangle \mathrm{Cu}-\mathrm{EOC} / \mathrm{MWCNT}(\mathrm{Sun})$
$\square \mathrm{Cu}-\mathrm{EOC} / \mathrm{MWCNT}($ Bayer)-Cu

FIGURE 6: Generated electric voltage versus temperature difference for all investigated composites (filler concentration $30 \mathrm{wt} \%$ ) together with the indicated thermoelectric power in $\mu \mathrm{V} / \mathrm{K}$.
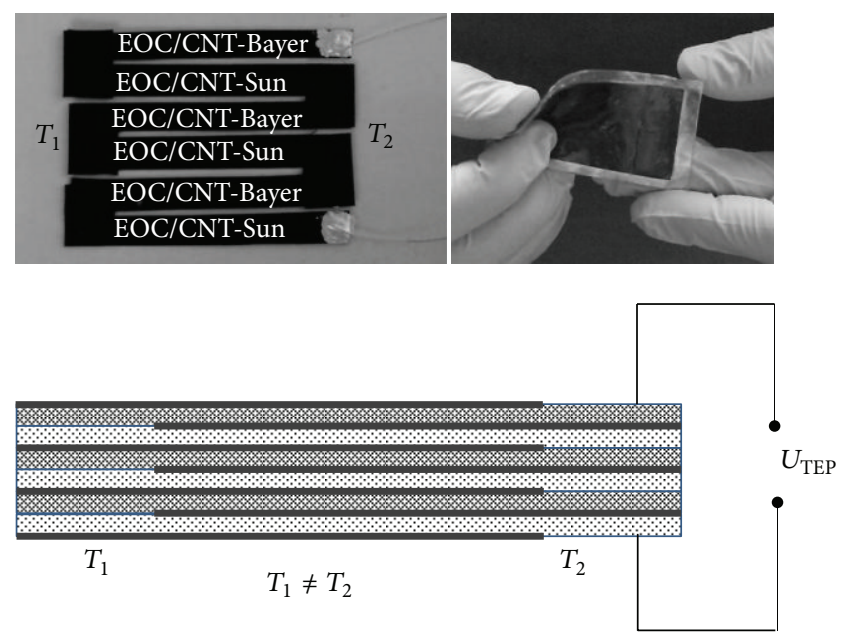

EOC/C70
EOC
EOC/CF

FIgURE 7: Thermoelectric device (thermopile) built up of MWCNT (Bayer) and CNF/EOC flexible composite films and the schematic diagram showing the material junctions in series alternating hot/cold temperatures with each junction.

junction. The measured temperature difference dependence of thermopile output voltage in the range of temperature difference -15 to $25^{\circ} \mathrm{C}$ is presented in Figure 8 .

Our results showing the through-thickness thermoelectric properties of continuous CNF/EOC and MWCNT/EOC composites demonstrate that the electrical conductivity of polymer composites can be significantly increased by incorporating conductive nanoparticles, while the thermal conductivity increases moderately, in particular in case of MWCNT(Sun) filling. This behavior results probably from prevailing thermally disconnected but electrically well connected dispersed nanotubes. The low thermal conductivity of the composites contributes to a high figure of merit at room temperature. The decisive role of nanocomposite filler, the possible modification of its properties by a proper functionalization, dispersion, and concentration or arrangement into a segregated entangled network, makes it feasible to tune thermoelectric properties in favor of thermoelectric efficiency.

\section{Conclusions}

We have prepared deformable composites composed of multiwalled carbon nanotubes or carbon nanofibers and ethylene-octene copolymer. Their thermoelectric properties-the electric and thermal conductivity and the electric voltage produced per degree temperature differencewere measured. The calculated thermoelectric power values for MWCNT(Bayer)/EOC $(6.4 \mu \mathrm{V} / \mathrm{K}), \mathrm{MWCNT}$ (Sun)/EOC $(13.3 \mu \mathrm{V} / \mathrm{K})$, and $\mathrm{CNF} / \mathrm{EOC}(14.2 \mu \mathrm{V} / \mathrm{K})$ are in comparison with the thermoelectric power of classical metallic thermoelectrics low, but their thermal conductivity below $1 \mathrm{~W} / \mathrm{mK}$ allows for a sustained temperature difference across the 


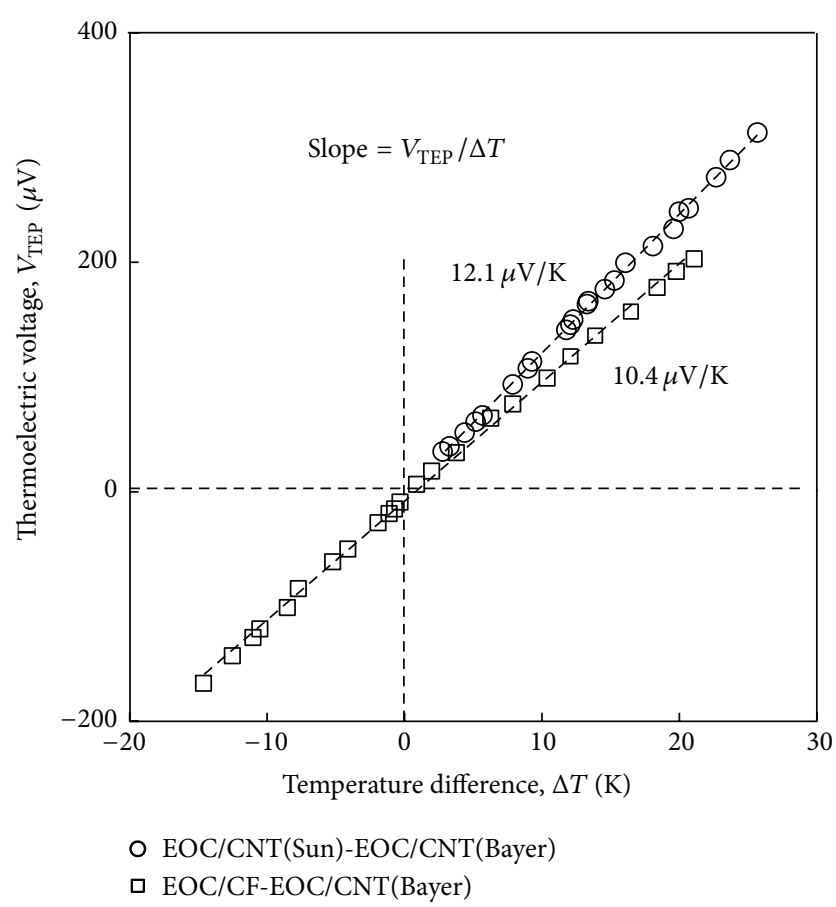

Figure 8: Temperature difference dependence of generated electric voltage by MWCNT(Sun)/EOC-MWCNT(Bayer)/EOC and MWCNT(Bayer)/EOC-CNF/EOC thermopiles.

composite. Moreover, the composite films are flexible and the created thermopile can be adjusted easily to a limited space and/or shape. Thus the combination of mechanical and thermoelectric properties of the composites may be advantageous, for instance, in applications where sources of waste heat have arbitrary shapes.

\section{Conflict of Interests}

The authors declare that they have no conflict of interests.

\section{Acknowledgments}

This project was supported by an internal Grant from TBU in Zlin no. IGA/FT/2013/018 funded by the resources of Specific University Research, by the Operational Program Research and Development for Innovations cofunded by the European Regional Development Fund (ERDF), by the National Budget of the Czech Republic within the framework of the Centre of Polymer Systems Project (registration no. CZ.1.05/2.1.00/03.0111), by the Operational Program "Education for Competitiveness" cofunded by the European Social Fund (ESF) and the National Budget of the Czech Republic within the "Advanced Theoretical and Experimental Studies of Polymer Systems" project (registration no. CZ.1.07/2.3.00/20.0104), and by the fund of Institute of Hydrodynamics AV0Z20600510.

\section{References}

[1] B. I. Ismail and W. H. Ahmed, "Thermoelectric power generation using waste-heat energy as an alternative green technology," Recent Patents on Electrical Engineering, vol. 2, no. 1, pp. 27-39, 2009.

[2] C. A. Hewitt, A. B. Kaiser, S. Roth, M. Craps, R. Czerw, and D. L. Carroll, "Multilayered carbon nanotube/polymer composite based thermoelectric fabrics," Nano Letters, vol. 12, no. 3, pp. 1307-1310, 2012.

[3] C. A. Hewitt, A. B. Kaiser, S. Roth, M. Craps, R. Czerw, and D. L. Carroll, "Varying the concentration of single walled carbon nanotubes in thin film polymer composites, and its effect on thermoelectric power," Applied Physics Letters, vol. 98, no. 18, Article ID 183110, 2011.

[4] C. Yu, Y. S. Kim, D. Kim, and J. C. Grunlan, "Thermoelectric behavior of segregated-network polymer nanocomposites," Nano Letters, vol. 8, no. 12, pp. 4428-4432, 2008.

[5] J. Chen, X. Gui, Z. Wang et al., "Superlow thermal conductivity 3D carbon nanotube network for thermoelectric applications," ACS Applied Materials and Interfaces, vol. 4, no. 1, pp. 81-86, 2012.

[6] G. P. Moriarty, J. N. Wheeler, C. Yu, and J. C. Grunlan, "Increasing the thermoelectric power factor of polymer composites using a semiconducting stabilizer for carbon nanotubes," Carbon, vol. 50, no. 3, pp. 885-895, 2012.

[7] D. D. Freeman, K. Choi, and C. Yu, "N-type thermoelectric performance of functionalized carbon nanotube-filled polymer composites," PLoS ONE, vol. 7, Article ID e47822, 2012.

[8] C. Bounioux, P. Diaz-Chao, M. Campoy-Quiles et al., "Thermoelectric composites of poly(3-hexylthiophene) and carbon nanotubes with a large power factor," Energy and Environmental Science, vol. 6, pp. 918-925, 2013.

[9] Y. Du, S. Z. Shen, K. Cai, and P. S. Casey, "Research progress on polymer-inorganic thermoelectric nanocomposite materials," Progress in Polymer Science, vol. 37, pp. 820-841, 2012.

[10] G. H. Kim, L. Shao, K. Zhang, and K. P. Pipe, "Engineered doping of organic semiconductors for enhanced thermoelectric efficiency," Nature Materials, vol. 12, pp. 719-723, 2013.

[11] O. Bubnova and X. Crispin, "Towards polymer-based organic thermoelectric generators," Energy and Environmental Science, vol. 5, pp. 9345-9362, 2012.

[12] N. Toshima, N. Jiravanichanun, and H. Marutani, "Organic thermoelectric materials composed of conducting polymers and metal nanoparticles," Journal of Electronic Materials, vol. 41, pp. 1735-1742, 2012.

[13] R. Yue, S. Chen, C. Liu et al., "Synthesis, characterization, and thermoelectric properties of a conducting copolymer of 1,12bis(carbazolyl)dodecane and thieno[3,2-b]thiophene," Journal of Solid State Electrochemistry, vol. 16, no. 1, pp. 117-126, 2012.

[14] K. Chatterjee, M. Mitra, K. Kargupta, S. Ganguly, and D. Banerjee, "Synthesis, characterization and enhanced thermoelectric performance of structurally ordered cable-like novel polyaniline-bismuth telluride nanocomposite," Nanotechnology, vol. 24, Article ID 215703, 2013.

[15] G. P. Moriarty, S. De, P. J. King et al., "Thermoelectric behavior of organic thin film nanocomposites," Journal of Polymer Science B, vol. 51, pp. 119-123, 2013.

[16] C. Yu, K. Choi, L. Yin, and J. C. Grunlan, "Light-weight flexible carbon nanotube based organic composites with large thermoelectric power factors," ACS Nano, vol. 5, no. 10, pp. 7885-7892, 2011. 
[17] Z. Antar, J. F. Feller, H. Noël, P. Glouannec, and K. Elleuch, "Thermoelectric behaviour of melt processed carbon nanotube/ graphite/poly(lactic acid) conductive biopolymer nanocomposites (CPC)," Materials Letters, vol. 67, no. 1, pp. 210-214, 2012.

[18] P. Slobodian, P. Riha, A. Lengalova, and P. Saha, "Compressive stress-electrical conductivity characteristics of multiwall carbon nanotube networks," Journal of Materials Science, vol. 46, no. 9, pp. 3186-3190, 2011.

[19] P. Slobodian, P. Riha, and P. Saha, "A highly-deformable composite composed of an entangled network of electricallyconductive carbon-nanotubes embedded in elastic polyurethane," Carbon, vol. 50, pp. 3446-3453, 2012.

[20] J. E. Lozano, Fruit Manufacturing: Scientific Basis, Engineering Properties, and Deteriorative Reactions of Technological Importance, Springer, New York, NY, USA, 2006.

[21] P. Svoboda, R. Theravalappil, S. Poongavalappil et al., "A study on electrical and thermal conductivities of ethyleneoctene copolymer/expandable graphite composites," Polymer Engineering and Science, vol. 52, pp. 1241-1249, 2012. 

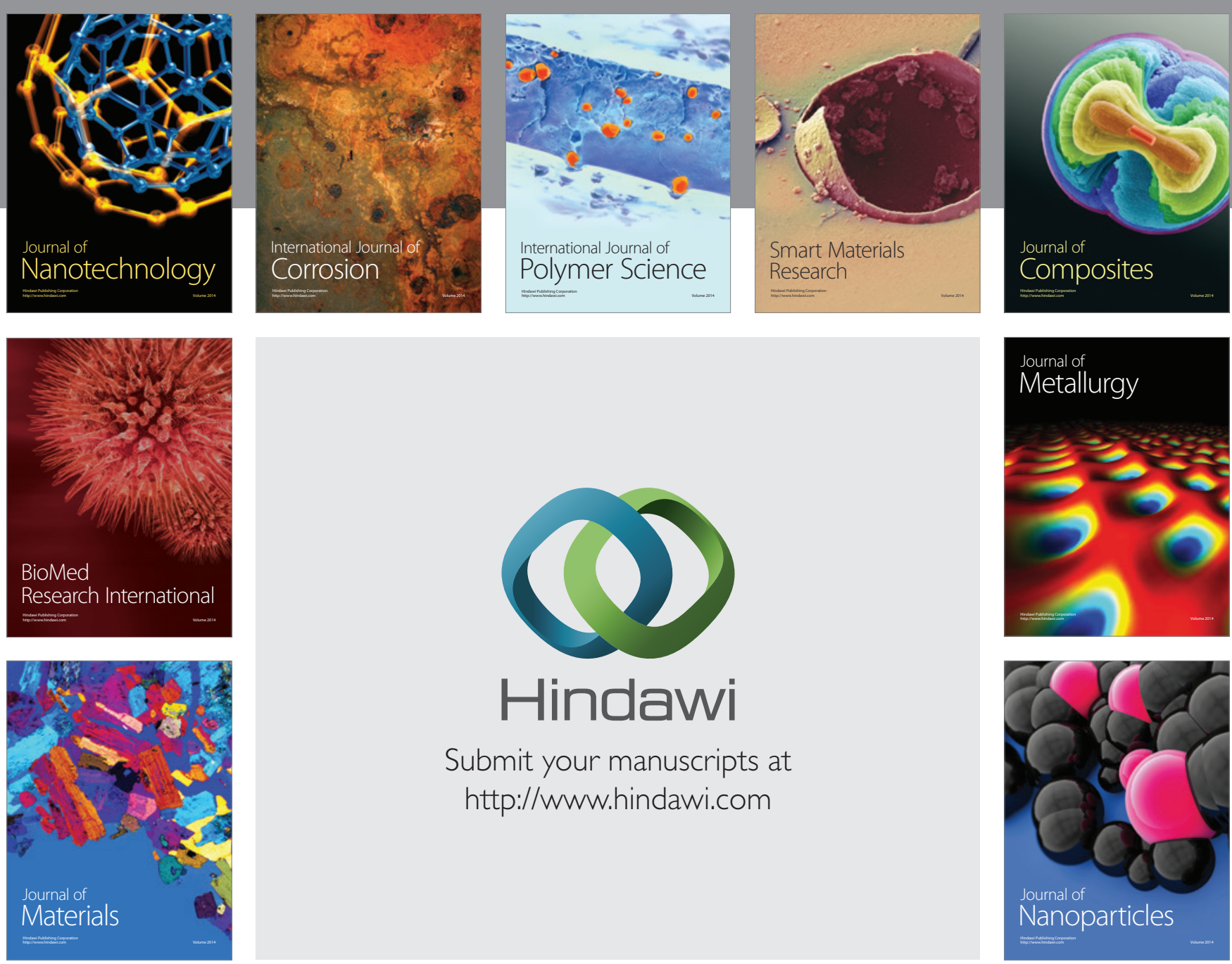

Submit your manuscripts at http://www.hindawi.com
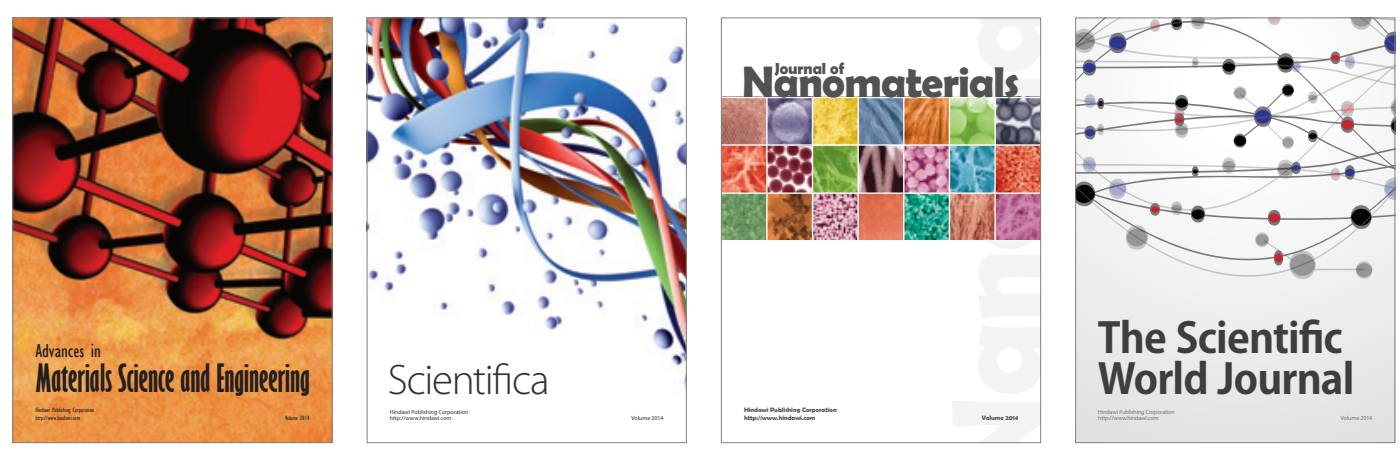

\section{The Scientific World Journal}
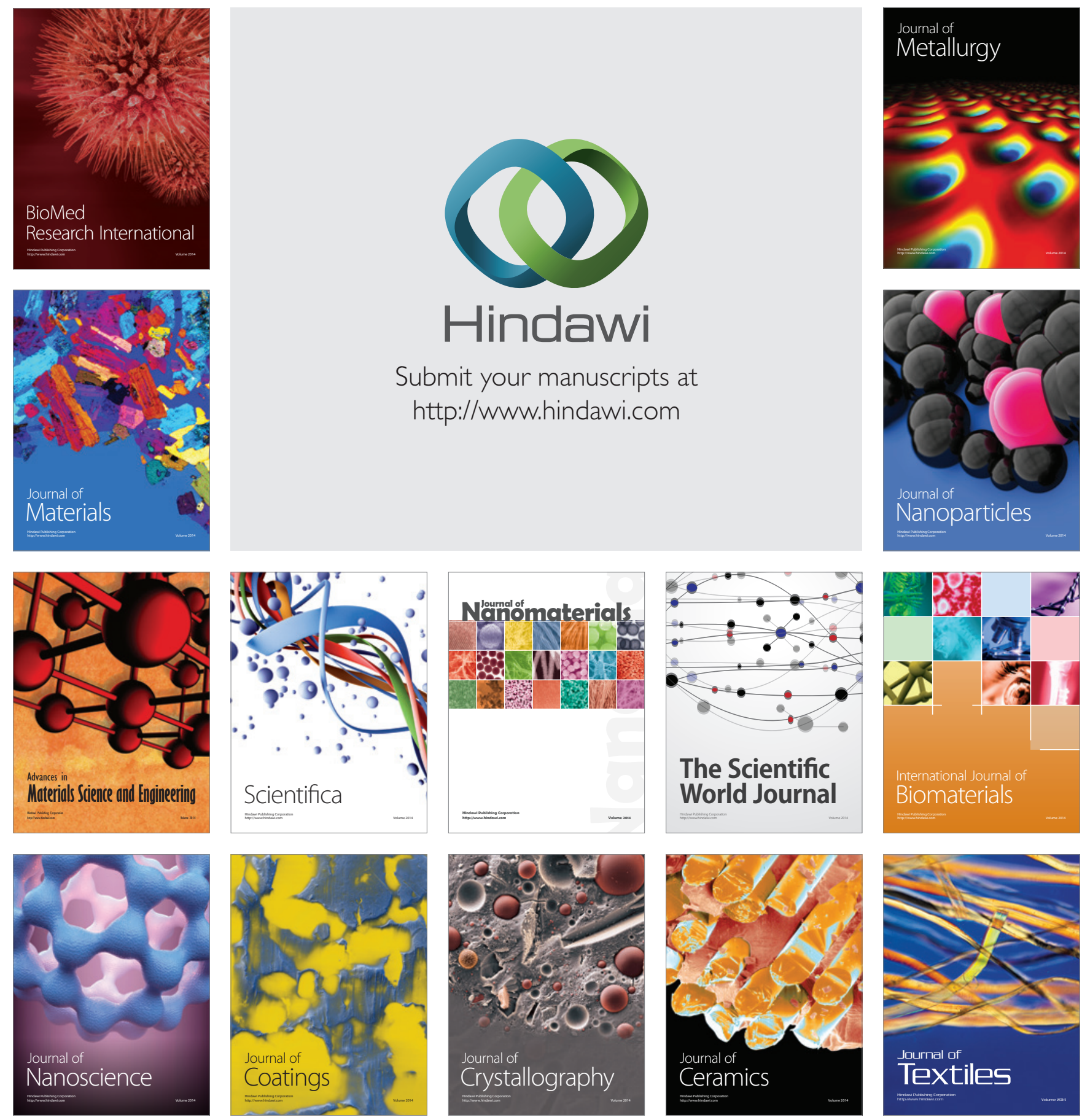